\title{
Tough choices: private sale of drugs in public hospitals
}

\author{
Colleen M. Flood LLM SJD, Lorian Hardcastle LLB LLM
}

Previously published at www.cmaj.ca

I $\mathrm{n}$ their efforts to sustain publicly funded health care, governments are increasingly deciding that some drugs are not sufficiently beneficial to merit public funding. ${ }^{1}$ For example, the Ontario government has elected not to fund bortezomib. ${ }^{2}$ The administration of such cancer drugs requires nursing staff and supervision and, with drugs such as ibritumomab, nuclear medicine facilities. Because of the cost of having drugs administered privately and the limited number of private clinics in Canada, some patients wish to pay to have these drugs administered in public hospitals. Until recently, as a matter of policy, public hospitals in Canada did not allow this, although some are now reportedly allowing such sale.

In this article, we discuss what Canadian provinces can do in terms of legislation, what they should do in terms of policy and what they may be compelled to do if there is a successful challenge under the Canadian Charter of Rights and Freedoms. Although we refer to Ontario's statutes, our conclusions are of broader interest because all Canadian provinces have legislation that limits the private sector. Furthermore, all jurisdictions with public health insurance struggle to determine which drugs are sufficiently cost-effective to attract public funding. ${ }^{3}$ Even in the United States, with its greater reliance on private insurance, the marginal effectiveness and high cost of new drugs is leading some to question the ethics and the policy effects of selling these drugs. ${ }^{4}$

\section{What can governments do? The statutory context}

To receive funding under the Canada Health Act, provinces must publicly cover "medically necessary" drugs within hospitals. ${ }^{5}$ Because this term is not defined, whatever drugs a province insures are typically regarded as medically necessary. The federal government could contest a decision not to insure a drug, particularly when there is clear evidence of effectiveness or when other provinces fund the same drug. But challenges to a province's decisions vis-à-vis medical necessity are very unusual. ${ }^{6}$

Nonetheless, provincial legislation may constrain a government's policy choices (unless such legislation or regulation is changed). For example, Ontario's Commitment to the Future of Medicare Act prohibits payment "for an insured service rendered to an insured person." Although this statute does not empower public hospitals to sell uninsured services, it does

\section{Key points}

- There is pressure on Canadian hospitals to permit patients to pay privately for drugs that are not publicly funded (and thus not considered "medically necessary").

- The main arguments against private payment for drugs in public hospitals focus on concerns about equal treatment and the impact on the public health care system.

- The main arguments in favour of private payment focus on patient safety, access to potentially beneficial drugs and personal liberty.

- The tension over the boundary between the public and private spheres is likely to worsen as governments seek to curb public spending by more stringently reviewing which drugs are publicly funded.

- If there is a Charter challenge, governments will have difficulty amassing clear empirical evidence about the deleterious effects on the public system.

not prohibit it. However, with respect to in-patients, insured services are defined to include any "drugs, biologicals and related preparations that are prescribed by an attending physician ... in accordance with accepted practice and administered in a hospital." ${ }^{\prime}$ Thus, in our view, it would likely be necessary to amend this provision to allow public hospitals to charge inpatients for drugs. ${ }^{9}$

\section{The argument against private payment}

Some would argue that allowing the sale of private drugs in public hospitals is permissible because inequality already exists within public hospitals. Canadians generally access private services that are not deemed medically necessary in facilities outside the public system and, historically, from physicians who are not employed in the public system. Although public hospitals in other jurisdictions (e.g., England and Australia) have private wings where such services are provided, Canada maintains a sharper distinction between public and private sectors. Thus, even if Canadians tolerate some unequal treatment in health care, they may not tolerate it in a public hospital. However, inequality already exists

From the Faculty of Law, University of Toronto, Toronto, Ont. and the Canadian Institutes of Health Research, Institute for Health Services and Policy Research (Flood), Ottawa, Ont.; and the University of Toronto (Hardcastle), Toronto, Ont.

CMAJ 2010. DOI:10.1503/cmaj.081137 
within public hospitals. For example, the Workplace Safety and Insurance Board provides pemetrexed (a cancer drug) to patients in hospital whose cancer is related to exposure in the workplace ${ }^{10}$ but not to other patients. The counter-response: Does one example of inequality justify another?

The second argument against allowing private payment for drugs in public hospitals is that it negatively affects the public system. The concern is not with the manufacture, distribution and sale of the drugs per se. In contrast to a private tier for medical services - which diverts resources such as physicians from the public sector ${ }^{11}-$ it is usually possible to manufacture more drugs in a short time to cover increased demand. Our concern is the time spent by clinicians prescribing or administering uninsured drugs, time that takes them away from supplying medically necessary services to public patients. However, we are aware of no empirical evidence that robustly defines the extent of public resources necessary to provide drug infusions to private patients. Nonetheless, some countries remain concerned about these effects. For example, the New Zealand government, having decided to limit a patient's course of treatment with trastuzumab to nine weeks ${ }^{12}$ subsequently did not allow patients to pay for the drug within public hospitals because of a concern about draining public resources..$^{13}$ This is in contrast to a similar situation in England, where a report from the National Health Service recommended that such sales be permitted. ${ }^{14}$

The sale of uninsured drugs may also undermine confidence in medicare. People may find it difficult to accept that drugs being sold within public hospitals are not medically necessary. This may increase pressure on public formularies to include these drugs, despite concerns about cost-effectiveness. Finally, allowing the sale of uninsured drugs could erode political support for a high standard of care in the public system when the people who are able to pay for drugs no longer lobby for public funding. The extent to which this will occur is likely tied to the price of the drugs (even the wealthy may struggle to pay for very expensive drugs) and the extent to which private health insurance will cover drugs that are not on provincial formularies.

\section{The argument supporting private payment}

In support of allowing private payment for drugs in public hospitals are arguments about access and patient safety. For example, desperate patients may seek drug infusion in a family physician's office or by untrained public hospital staff. Issues may also arise when patients require the administration of both an uninsured and an insured drug and should receive them simultaneously; yet they receive them in separate facilities at separate times. Additional safety concerns arise when a patient is receiving treatment from multiple practitioners, and the medical records are kept in different locations. ${ }^{15}$ Restrictions on the sale of uninsured drugs may in some cases prevent not only safe access, but also any access. Patients may not be well enough to travel to one of a limited number of private clinics, or travelling may cause financial hardship or separation from the emotional support of family members.
The second argument in favour of allowing private payment for drugs within public hospitals is grounded in individual liberty. Canadian laws and values allow a private health care sector - for pharmaceuticals, home care, some longterm care and services deemed not medically necessary grounded in such individualistic values as liberty, choice and autonomy. This liberty produces inequality in health care based on ability to pay. To many Canadians, this inequality is unobjectionable, provided it does not worsen the situation of those who depend on publicly financed care. This approach was adopted by the majority of the Supreme Court of Canada in Chaoulli v. Quebec, which concluded that the ban on private insurance infringed the right to security, and that allowing private insurance would not threaten the public system. ${ }^{16}$ Cancer Care Ontario's Working Group on the Delivery of Oncology Medications for Private Payment in Ontario Hospitals appears to take this approach as well. ${ }^{17}$ Some public hospitals in Ontario are now relying on these recommendations in the sale of uninsured drugs while they await guidance from the provincial government. However, it is too early to determine whether it is in fact possible to allow patients to purchase uninsured drugs in public hospitals without deleterious effects on the pubilc health care system. ${ }^{18}$

\section{What might governments be compelled to do? The Charter}

Banning private payment for drugs in public hospitals may violate the right to "life, liberty and security of the person," as set out in the Canadian Charter of Rights and Freedoms. ${ }^{19}$ A patient could successfully claim that these rights were engaged by the safety concerns or psychological stress associated with having to travel to private clinics. However, claimants may have a problem establishing that these rights were deprived as a result of government action. In $R$. v. Morgentaler, the Supreme Court of Canada ruled that government actions that block or deny access to health care - in that case, administrative obstacles to abortion services - are unconstitutional. ${ }^{20}$ However, a Charter challenge is more likely to succeed when government is considered to have actively intervened to prevent access to care. It would be more difficult to advance a challenge when government passively refuses to deliver privately purchased drugs in private hospitals. However, a refusal by government to allow infusion of an uninsured drug in a public hospital when a patient cannot travel safely to a private clinic could be construed as active intervention.

If an applicant did establish this connection, the government would have the onerous task of proving that such denial was a "reasonable limit." ${ }^{20}$ The objective of protecting a public insurance plan that fosters equality regardless of ability to pay is pressing; however, a court may question whether the legislation is rationally connected to this goal because of the difficulties inherent in conducting empirical research on the negative impact of public hospitals selling uninsured drugs (cause and effect in such complex systems is extremely difficult to establish). 


\section{Conclusion}

Governments must make increasingly tough choices in the face of an influx of expensive new drugs and the strictures of public finance - pressures that are likely to be exacerbated in the future. These choices have created pressure from people who wish to purchase these drugs in public hospitals. There are no easy conclusions, but on balance we argue that uninsured drugs should not be sold in public hospitals because of the possible negative effects on the public health care system. We are particularly worried that Canadians with private insurance for high-cost drugs will be less concerned about these drugs being exclued from the public plan. However, this argument may not sustain a Charter challenge because governments have a difficult battle given the lack of clear empirical evidence on the deleterious effects on the public health care system.

This article has been peer reviewed.

Competing interests: None declared.

Contributors: Both authors contributed substantially to the conception, design, drafting and revision of this article. Both authors approved the final version submitted for publication.

\section{REFERENCES}

1. Laupacis A. Inclusion of drugs in provincial drug benefit programs: who is making these decisions and are they the right ones? CMAJ 2002;166:44-7.

2. Benzie R. Big cancer bills covered. Toronto Star Healthzone. 2008 July 2. Available: http://healthzone.ca/health/article/452457 (accessed 2009 Dec. 15).

3. Chafe R, Dhalla IA, Dobrow M, et al. Accessing unfunded cancer drugs in publicly funded hospitals. Lancet Oncol 2009;10:306-7.

4. Kolata G, Pollack A. Costly cancer drug offers hope, but also a dilemma. New York Times. 2008 July 6. Available: www.nytimes.com/2008/07/06/health/06 avastin.html?_r=2\&adxnnl=1\&oref=slogin\&adxnnlx=1216059031-GQpQGOvi7tC6 TBHJWt+7cg (accessed 2009 Dec. 15).

5. Canada Health Act, R.S.C. 1985, c. C-6, s. 2, 7, 9.

6. Choudhry S. Bill 11, the Canada Health Act and the social union: the need for institutions. Osgoode Hall Law J 2000;38:39-76.

7. Commitment to the Future of Medicare Act, S.O. 2004, c. 5, s. 10(5).

8. Health Insurance Act, R.S.O. 1990, c. H-6, s. 11.2(1) and General Regulation, R.R.O. 1990, Reg 552, s 7.

9. Health Insurance Act, R.S.O. 1990, c. H-6, s. 11.2(1) and General Regulation, R.R.O. 1990, Reg 552, s 8.

10. Khoo K, Colucci R, Hryniuk W, et al. The new wave of cancer drugs. In: Report card on cancer in Canada. Vol 10. Toronto (ON): Cancer Advocacy Coalition; 2007. p. 43.

11. Wright C. Different interpretations of 'evidence' and implications for the Canadian healthcare system. In: Flood CM, Roach K, Sossin L, editors. Access to care: access to justice: the legal debate over private health insurance in Canada. Toronto (ON): University of Toronto Press; 2005. p. 221-2.

12. Walsh and Ors v. Pharmac, [2008] NZHC 441.

13. Provider selection protocols. Wellington (New Zealand): New Zealand Ministry of Health; 2005. p. 9-10.

14. Richards M. Improving access to medicines for NHS patients. London (England): Secretary of State for Health; 2008.

15. The Bristol Royal Infirmary Inquiry. Learning from Bristol: the report of the public inquiry into children's heart surgery at the Bristol Royal Infirmary 1984-1995. London (England): Secretary of State for Health; 2001.

16. Chaoulli v. Quebec, [2005] 1 S.C.R. 791.

17. Cancer Care Ontario. Report of the Provincial Working Group on the Delivery of Oncology Medications for Private Payment in Ontario Hospitals. Toronto (ON): Cancer Care Ontario; 2006.

18. Cancer Care Ontario. Unfunded intravenous cancer drugs. Available: http://cancercare .on.ca/cms/One.aspx?portalid=1377\&pageid=11822\# (accessed 2010 Jan. 29).

19. The Canadian Charter of Rights and Freedoms, Part I of the Constitution Act, 1982, being Schedule B to the Canada Act 1982 (U.K.), 1982, c 11.

20. R. v. Morgentaler, [1988] 1 S.C.R. 30.

Correspondence to: Colleen Flood, Faculty of Law, University of Toronto, 39 Queen's Park E, Toronto ON M5S 2C3;

colleen.flood@utoronto.ca

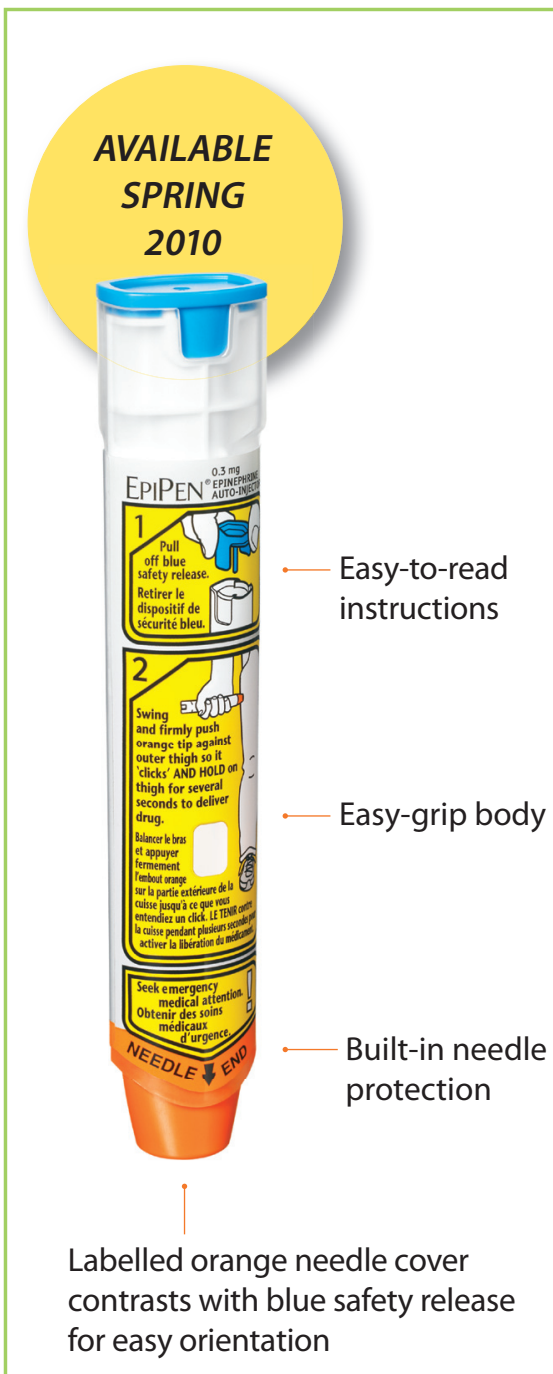

Important Safety Information

EpiPen॰ and EpiPen* Jr Auto-injectors are indicated for the emergency treatment of anaphylactic reactions in patients who are determined to be at increased risk for anaphylaxis, including individuals with a history of anaphylactic reactions. They are intended for immediate selfadministration for the emergency treatment of severe allergic reactions (Type I), including anaphylaxis associated with foods, stinging and biting insects, medications, latex, other allergens, and for idiopathic and exercise-induced anaphylaxis. Selection of the appropriate dosage strength is determined according to patient body weight.

There are no absolute contraindications to the use of epinephrine in a life-threatening allergic situation. Epinephrine use should be avoided in patients with cardiogenic, traumatic, or hemorrhagic shock; cardiac dilation; and/or cerebral arteriosclerosis. Epinephrine use should be avoided in patients with organic brain damage and in patients with narrow-angle glaucoma. Administer with caution to elderly or hyperthyroid individuals, pregnant women, and individuals with cardiovascular disease or diabetes.

Adverse reactions of epinephrine include transient, moderate anxiety; feelings of over stimulation; apprehensiveness; restlessness; tremor; weakness; shakiness; dizziness; sweating; tachycardia; palpitations; pallor; nausea and vomiting; headache; and/or respiratory difficulties.

EpiPen and EpiPen Jr Auto-injectors are designed as emergency supportive therapy only. They are not a replacement or substitute for subsequent medical or hospital care, nor are they intended to supplant insect venom hyposensitization. 